\title{
A Educação de Adultos no âmago da aprendizagem ao longo da vida: uma visão económica ou emancipadora?
}

\author{
Daniela Silva \\ Instituto de Educação, Universidade do Minho
}

\begin{abstract}
Resumen
Atualmente, assistimos à emergência de conceitos que proliferam em muitas iniciativas e políticas de educação de adultos, tais como: aprendizagem ao longo da vida, espaço europeu de educação, competências, benchmarks. Nesta comunicação pretendemos não só compreender diacronicamente $\mathrm{a}(\mathrm{s})$ genealogias destes conceitos como também desvendar a perspetiva teórica subjacente a cada um. Na génese destes conceitos incluem-se os contributos de vários organismos internacionais, nomeadamente da União Europeia. Esta comunicação tem como objetivos refletir sobre a) o fenómeno da globalização, a construção do espaço europeu de educação e a definição de benchmarks no campo da educação de adultos, b) as diferentes normas e diretrizes emanadas da União Europeia no sector da educação de adultos que apelam à construção da aprendizagem ao longo da vida, c) as lógicas que se encontram, explicita ou implicitamente, nas diretrizes emanadas pela União Europeia. Em termos metodológicos, esta reflexão é elaborada a partir da análise de conteúdo a diversos documentos da Comissão das Comunidades Europeias publicados desde o início do milénio, nomeadamente: a) o Memorando sobre a aprendizagem ao Longo da Vida, b) Tornar o espaço europeu de aprendizagem ao longo da vida uma realidade, c) Educação de Adultos: nunca é tarde para aprender, d) Pograma Educação/Formação 2010, entre outros. Os documentos indicam-nos que através da aposta na educação de adultos alicerçada no paradigma da aprendizagem ao longo da vida, a Europa cria condições para o desenvolvimento do Espaço Europeu de Educação e para a conquista de uma posição privilegiada, económica e cultural, a nível mundial. Uma das tónicas dominantes, transversal a muitos documentos, é precisamente o enfoque nas dimensões economicistas através de uma subordinação da educação de adultos a princípios de natureza económica, negligenciando as dimensões associadas a uma vertente mais humanista e emancipatória da educação.
\end{abstract}

Palabras clave: Educação de adultos, aprendizagem ao longo da vida e espaço europeu de educação

\section{Introdução}

Hodiernamente, assistimos à emergência de conceitos que proliferam em muitas iniciativas e políticas de educação de adultos, tais como: aprendizagem ao longo da vida, espaço europeu de educação, competências, benchmarks. Nesta comunicação pretendemos não só compreender diacronicamente $\mathrm{a}(\mathrm{s})$ genealogias destes conceitos como também desvendar a perspetiva teórica subjacente a cada um. Na génese destes conceitos incluem-se os contributos de vários organismos internacionais, nomeadamente da União Europeia. Esta comunicação tem como objetivos refletir sobre a) o fenómeno da globalização, a construção do espaço europeu de educação e a definição de benchmarks no campo da educação de adultos, b) as diferentes normas e diretrizes emanadas da União Europeia no sector da educação de adultos que apelam à construção da aprendizagem ao longo da vida, c) as lógicas que se encontram, explicita ou implicitamente, nas diretrizes emanadas pela União Europeia. Em termos metodológicos, esta reflexão é elaborada a partir da análise de conteúdo a diversos documentos da Comissão das Comunidades Europeias publicados desde o início do milénio, nomeadamente: a) o Memorando sobre a aprendizagem ao Longo da Vida, b) Tornar o espaço europeu de aprendizagem ao longo da vida uma realidade, c) Educação de Adultos: nunca é tarde para aprender, d) Pograma Educação/Formação 2010, entre outros.

\section{A União Europeia e a construção do Espaço Europeu de Educação - novos desafios na educação de adultos}

Desde o inverno de 1986 que Portugal tem vindo a beneficiar do designado Fundo Social Europeu, o qual compreende um conjunto de quadros comunitários de apoio que, juntamente com o Estado Português, têm vindo a proporcionar um impulso no campo da educação /formação de adultos. A influência das políticas educativas da União Europeia nas políticas educativas de adultos portuguesas tem constituído objeto de estudo em várias investigações. Entre estas investigações destacamos os trabalhos de A. Teodoro (2001), F. Antunes (2004, 2008), L. Lima (2010), P. Guimarães (2010), R. Barros (2011), C. Cavaco (2009) e P. Ávila (2008).

Um dos contributos importantes sobre a genealogia da europeização das políticas de educação e formação, é fornecido por F. Antunes (2008). Segundo a autora, a intervenção da política comunitária no campo da educação é dividida em duas etapas e quatro fases: a $1^{\mathrm{a}}$ etapa ocorre entre a década de 70 e prolonga-se até 1992 com a assinatura do Tratado da União Europeia. A $2^{\mathrm{a}}$ etapa, começa com o Tratado e prolonga-se até aos dias de hoje. 
No âmbito da $1^{\mathrm{a}}$ etapa, a autora considera a existência de duas fases. Uma primeira fase que decorre de 1971 até 1986, na qual se regista o "primeiro afloramento de iniciativas no campo da educação ao nível comunitário" (ibidem, 17) e onde ocorre a institucionalização da educação como área de cooperação e de ação comunitária.

A segunda fase tem início em meados da década de 80, com o Ato Único Europeu e prolonga-se até 1992. Nesta segunda fase, dá-se a intensificação da intervenção da política comunitária no setor da educação através dos Programas de Ação Comunitários. É precisamente nesta $2^{\mathrm{a}}$ fase que a autora situa o início do processo de europeização da educação no contexto comunitário, como refere F. Antunes (2008: 18) “é possível identificar dimensões da intervenção política pública em educação em que as instituições da Comunidade/União Europeia e os sistemas políticos nacionais podem ser vistos como tendendo a constituir uma totalidade (cf. Andersen \& Elianssen, 1993a, 1993b), não forçosamente integrada ou isenta de conflitos, mas, pelo contrário, consideravelmente fragmentada, difusa e contraditória”. Assim sendo, a partir do Ato Único Europeu, intensificam-se e constroem-se, a partir de um conjunto de entendimentos comuns, orientações para todos os Estados-Membros "tendentes a estabelecer uma matriz discursiva que redefine a educação em torno de um conjunto de vectores ou polos discursivos ideológicos" (idem, ibidem).

Na segunda etapa ocorre a edificação de uma política comunitária na área da educação e do Espaço Europeu de Educação. À semelhança da etapa anterior, esta também é constituída por mais duas fases: a terceira que ocorre entre o ano de 1992 e termina nos anos de 1998/1999 e uma quarta que se inicia em finais da década de noventa e se prolonga até aos nossos dias.

A terceira fase é caracterizada pela ampliação da esfera de intervenção da União Europeia. Esta fase é multifacetada e regista um conjunto de inovações, estratégias que redimensionam o papel da intervenção comunitária no campo da educação não só ao nível das competências, mas também ao nível da constituição de organismos, do desenvolvimento de programas de ação, da publicação de documentação orientadora dos “entendimentos comuns” para a educação e legitimando o seu campo de ação. Decorrente do Tratado de Maastricht e, mais tarde do tratado de Amesterdão (1997), são definidas competências específicas da União Europeia em matéria de educação. A nível organizacional, a ênfase recai no Conselho da União Europeia, sendo este constituído pelos Ministros da Educação dos Estados-membros adquirindo o estatuto de um dos órgãos da União.

No campo de ação desta dinamização do setor educativo, são publicados dois livros brancos: a) um sobre o Crescimento, Competitividade e Emprego. Os desafios e as pistas para entrar no séc. XX e b) Ensinar e Aprender - Rumo à Sociedade Cognitiva (1995). Estas obras vêm contribuir para uma futura regulamentação dos Estados-Membros no campo da Educação de Adultos, em particular o segundo Livro Branco sobre a Educação e a Formação. O seu objetivo é "contribuir, com as políticas de educação e formação dos Estados-Membros, para colocar a Europa na via da sociedade cognitiva, baseada na aquisição de conhecimentos, onde ensinar e aprender são um processo contínuo ao longo da vida”. A ideia nuclear de sociedade cognitiva assenta na projeção de uma sociedade onde cada indivíduo pode construir a sua própria qualificação, reforçando o mérito da sua inteligência. Se atendermos à função que a educação aqui parece desempenhar, esta reduz-se a uma mera adaptação da educação aos contextos de trabalho, o que coloca a educação numa relação de subordinação face aos imperativos económicos, assentes numa racionalidade tecnocrata. A ideia de uma educação para a cidadania encontra-se, claramente, ausente na procura da "sociedade cognitiva". Esta leitura é também subsidiária do duplo desafio enunciado: "é económico na medida em que, aberta ao mundo, a União Europeia deve reforçar constantemente a sua competitividade, é social porque responde ao imperativo de luta contra a exclusão”. Esta fase representa uma amplificação do campo educativo no contexto de União Europeia, de uma orientação política e de um "pensamento programático ideológico [...] por orientações vistas como imperativas que decorrem das prioridades ou necessidades percepcionadas com origem na economia” (Antunes, 2008,20). Neste âmbito, emergem os conceitos de sociedade de aprendizagem, do conhecimento da informação ou aprendizagem ao longo da vida; definindo uma agenda e um novo mandato para a Educação no contexto comunitário das suas instituições.

A quarta fase, definida como a edificação, articulação sistémica de políticas do Espaço Europeu de Educação formal, reforça o processo de europeização das políticas educativas. A criação de um Espaço Europeu de Educação (Dale, 2008) desenvolve-se no âmbito de uma cooperação reforçada e no contexto em que a "União Europeia tende a ampliar e aprofundar a sua capacidade de actuação e influência redesenhando a fronteira da sua acção em termos quer de áreas políticas quer de limites territoriais” (Antunes, 2008).

Neste contexto, o espaço comunitário abre as suas fronteiras ao contexto europeu no seio dos processos de globalização, procurando "desenvolver um nível de atuação política, nos domínios da educação e da formação, de escala não apenas comunitária mas europeia” (Antunes, 2008: 22), designada por espaço europeu e de onde despoletam os programas, propostas, projetos e declarações políticas, cujos exemplos mais ilustrativos são o processo de Bolonha (1999) e o programa de Educação/Formação (2010).

O Memorando sobre a aprendizagem ao longo da vida e a comunicação da Comissão Tornar o espaço europeu de aprendizagem ao longo da vida uma realidade, vêm reforçar este projeto europeu. Defendendo uma nova era - a era do conhecimento - o Memorando vem colocar a Europa, no seu todo, num contexto de mudança. Assim, é definido que a "Europa está em transição para uma sociedade e uma economia assentes no conhecimento" (CCE, 2000:5). Porém, este conhecimento vem apelar a uma nova sociedade inspirada e orientada por princípios económicos, como 
esclarece o seguinte excerto: "Mais do que nunca, o acesso a informações e conhecimentos atualizados, bem como a motivação e as competências para usar esses recursos de forma inteligente em prol de si mesmo e da comunidade, estão a tornar-se a chave do reforço da competitividade da Europa e da melhoria da empregabilidade e da adaptabilidade da força de trabalho" (idem, ibidem).

Portanto, conhecimento, empregabilidade e adaptabilidade figuram conceitos chave na nova era do conhecimento e da aprendizagem ao longo da vida. Neste documento são também identificados os dois objetivos da aprendizagem ao longo da vida: "promover a cidadania ativa e fomentar a empregabilidade" (ibidem, 6). Ao longo do documento é frequente a associação do conceito de aprendizagem ao longo da vida com os conceitos de competência, empregabilidade, pelo que nos permite afirmar que assistimos à revalorização de um novo contexto educativo virado para a economia e para a empregabilidade, como nas fases anteriores definidas por F. Antunes (2008). O conceito de aprendizagem ao longo da vida passa a ser o motor de uma engrenagem assente numa lógica essencialmente económica, onde também se reforça o conceito de competência, associado ao contexto de trabalho. Esta aprendizagem é considerada em função das suas várias dimensões: formal, não-formal e informal. $\mathrm{O}$ desenvolvimento e a execução da aprendizagem ao longo da vida pressupõe uma combinação entre diferentes entidades, promovidas pelo estabelecimento de estratégias de cooperação e de parcerias, entre os governos dos países membros mas também da intervenção de órgãos locais, regionais e de organizações da sociedade civil. Sublinha-se, nesta agenda, o papel de que cada Estado-Membro não passa pela provisão desta aprendizagem ao longo da vida mas antes pelo papel de promotor e avaliador de um programa supranacional indutor de boas práticas num contexto comunitário.

Na construção da aprendizagem ao longo da vida, a Comissão define seis mensagens-chave de apoio à ação, sendo uma delas - mensagem 4 - dedicada ao objetivo de melhorar significativamente a forma como são entendidos e avaliados a participação e os resultados da aprendizagem, em especial da aprendizagem não-formal $e$ informal. A procura pela certificação das aprendizagens é justificada, deste modo: “os diplomas, os certificados e as qualificações são um importante ponto de referência para empregadores e indivíduos no mercado de trabalho e nas empresas. A crescente procura de mão-de-obra qualificada por parte dos empregadores e a concorrência cada vez mais acentuada entre indivíduos para conseguir e manter um emprego estão a induzir uma procura muito mais acentuada de formação reconhecida. Como modernizar mais eficazmente os sistemas e as práticas de certificação nacionais face às novas condições económicas e sociais tornou-se uma questão política e profissional importante no conjunto da União"(ibidem, 17, negrito no original).

Os conceitos de qualificações e certificações impõem-se neste sentido em articulação estreita com o mercado de trabalho, servindo, sobretudo, interesses económicos e não interesses ligados ao desenvolvimento pessoal e social de cada indivíduo.

A comunicação da Comissão Tornar o espaço europeu de aprendizagem ao longo da vida uma realidade vem ampliar a noção de aprendizagem ao longo da vida. Logo no início são introduzidos novos papéis à aprendizagem para além da sua relação com a empregabilidade presente no Memorando. Assim, os objetivos da aprendizagem passam a incluir "a cidadania ativa, o desenvolvimento individual e a inclusão social, bem como aspetos relacionados com o emprego" (CCE, 2001:4). A aprendizagem ao longo da vida adquire uma nova definição e passa a ser definida como: "toda a actividade de aprendizagem em qualquer momento da vida, com o objectivo de melhorar os conhecimentos, as aptidões $e$ competências, no quadro de uma perspectiva pessoal, cívica, social e/ou relacionada com o emprego" (ibidem, 10, itálico no original). Os conceitos-chave desta nova tendência de aprendizagem ao longo da vida e da sociedade do conhecimento são reforçados em torno de: empregabilidade, competências, valorização das aprendizagens e reconhecimento de competências.

Estes conceitos são fundamentais para a construção do Espaço Europeu de Educação e para o reforço do papel da Europa no contexto mundial, como refere o Comunicado: "em termos económicos, a empregabilidade e adaptabilidade dos cidadãos são vitais para que a Europa possa prosseguir o seu escopo de se tornar a sociedade do conhecimento mais competitiva e dinâmica do mundo" (ibidem, 7).

R. Dale (2008) analisa a relação entre a construção de um Espaço Europeu de Educação e a construção da "Europa” como entidade, a qual tem sido crucial para o desenvolvimento de uma política de educação europeia com claras repercussões nas políticas educativas dos Estados Membros. Um marco fundamental propiciador também de mudanças na natureza e envolvimento da União Europeia na política educativa foi a Declaração de Lisboa 2000. Esta declaração veio delinear um conjunto de marcos para a análise da construção do Espaço Europeu de Educação. Assim, R. Dale (2008, 21) identifica três estádios de desenvolvimento desse espaço europeu.

Na primeira fase, anterior à Declaração, denominada pelo autor de Pré-Lisboa: definir qualidade como base de comparação e decorrente da ausência de consenso sobre o conteúdo de educação, geraram-se condições para a emergência de "ferramentas de avaliação", possibilitando o surgimento de bases para o Espaço Europeu de Educação e para a construção de uma política educativa europeia. $\mathrm{O}$ interesse da União Europeia recai na definição de um conjunto de indicadores de qualidade no final dos anos 90. A importância destes indicadores reside no facto de "os indicadores serviram expressamente para 'permitir aos países aprenderem uns com os outros através da comparação de interesses comuns e diferenças partilhadas`, bem como, de os benchmarks servirem para dotar os políticos com pontos de referências” (Dale, 2008: 23). Todavia, esta valoração acabaria por se afastar de uma "avaliação de eficiência, no sentido da cooperação em função de objetivos comuns”. 
A segunda fase, coincidente com o Conselho de Lisboa, visa a construção do Espaço Europeu de Educação, através de uma nova metodologia: o Método Aberto de Coordenação (MAC). Procurando conciliar a diversidade nacional dos Estados Membros, este método pressupunha a existência de uma "convergência regional com diversidade nacional" (ibidem, 23). Esta nova metodologia implicava a fixação de orientações para a União, o estabelecimento de "indicadores e benchmarks quantitativos e qualitativos ao nível dos melhores do mundo e à medida das necessidades dos diferentes Estados- Membros e setores, como meio de comparar as melhores práticas”, a transposição destas “orientações para as políticas nacionais e regionais, definindo metas específicas” e a sua monitorização periódica, avaliação e revisão por pares (Dale, 2008). A definição de “benchmarks de desempenho (ou `boas práticas`) podem ser usadas internacionalmente para estabelecer limites proscritos/exclusivos para a ação dos Estados Membros e os benchmarks, enquanto ferramentas políticas, podem ser usadas para alinhar supranacionalmente as suas políticas” (ibidem, 26). O estabelecimento destes indicadores e dos benchmarks passam a funcionar como mecanismos de regulação tanto nacionais como supranacionais. A título de exemplo, e no âmbito da aprendizagem ao longo da vida, o Conselho da União Europeia definiu em 7 de Maio de 2003 que "na sociedade do conhecimento, todos os indivíduos têm de atualizar e complementar os seus conhecimentos, aptidões e competências ao longo da vida para poderem maximizar o seu desenvolvimento pessoal e manter e melhorar a sua situação no mercado de trabalho. Por conseguinte, até 2010, o nível médio de participação na aprendizagem ao longo da vida na União Europeia deverá corresponder pelo menos a $12,5 \%$ da população adulta em idade ativa (grupo etário dos 25 aos 64 anos)” (Conselho da União Europeia, 2003:6).

Todavia, a introdução de benchmarks e a regulação supranacional derivada do MAC, poderá, como nos alerta L. Lima (2010:46), revelar-se como "um método que se define como aberto mas que, na prática, evidencia poderosos instrumentos de convergência e de isomorfismo, baseados em múltiplos instrumentos, entre os quais a emulação e a competição, induzidas pela definição de benchmarks, por variados processos de monitorização, pilotagem e avaliação”.

A terceira e última fase designada pelo autor de Aprendizagem ao longo da vida como um Programa Integrado Único vem colmatar algumas gralhas da fase anterior, na medida em que volvidos cinco anos de vigência da segunda fase, os resultados alcançados e a revisão da agenda de Lisboa revelaram-se "pouco lisonjeiras” (Dale, 2008: 26).

Os resultados obtidos nos relatórios da Comissão Europeia, tanto no de 2004 como no de 2006, revelaram percentagens insuficientes de participação dos adultos no quadro da aprendizagem ao longo da vida, tendo, contudo, este último enfatizado a necessidade de acelerar a velocidade da implementação do programa de Educação e Formação 2010, a definição de metas e a melhoria da governação do programa. Face a estes resultados, tornava-se necessário uma "definição mais apertada das metas a atingir, em relação aos objetivos de desenvolvimento económico e a métodos alternativos de difusão e implementação de programas da UE” (Dale, 2008: 26).

Neste cenário de reorientação dos objetivos já traçados, a aposta da União Europeia recai num "programa de ação integrado no domínio da aprendizagem ao longo da vida" que passaria a constituir a base de uma nova geração de programas de Educação da União Europeia para o período de 2007-2013.

Em 2006 é então preparado um novo quadro comunitário designado de Quadro de Referência Estratégico Nacional (QREN). Integrado, neste ámbito, emerge o programa global de aprendizagem ao longo da vida para 2007-2013 definido pela Comissão das Comunidades Europeias a 23 de Outubro de 2006. Este programa intitula-se Educação de adultos: nunca é tarde para aprender. No Comunicado, o investimento na Educação de Adultos é justificado como uma necessidade de promover a participação dos adultos no quadro de uma aprendizagem ao longo da vida. A urgência de aumentar a participação dos adultos nas iniciativas do quadro da aprendizagem ao longo da vida continua a ser reforçada como um dos objetivos desta iniciativa.

No mesmo ano, a 24 de Novembro de 2006 é apresentado o Programa de Aprendizagem ao longo da vida no Jornal Oficial da União Europeia que vem reforçar o quadro da aprendizagem ao longo da vida e no âmbito da valorização do Espaço Europeu de Educação, situado à escala planetária, virado para as dimensões económicas através das potencialidades de um crescimento económico e da coesão social da sociedade do conhecimento. O conceito de competência adquire um protagonismo central neste programa, bem como é reforçada a indução de boas práticas e de indicadores de comparação entre os países do Espaço Europeu de Educação.

Atualmente, é reconhecido que estamos em presença de uma nova mutação paradigmática da educação para a aprendizagem, que vem conferir novos papéis à educação e um novo mandato bem diferente do proclamado no movimento da educação permanente (cf. Lima, 2010). Esta transição paradigmática é entendida, de acordo com R. Canário (2001) como "uma ruptura e não uma continuidade, inscreve-se e só é compreensível no quadro de um conjunto mais vasto de transformações de natureza social que afectaram a economia, o trabalho e a formação, no último quartel do século XX”. Todavia, esta rutura ainda não terá sido total tendo em conta, sobretudo, duas argumentações, como demonstra L. Lima (2010:45) “Em primeiro lugar porque o sistema económico e o sistema educativo continuam a revelar-se os principais agentes indutores da transição paradigmática[...]. Em segundo lugar porque um sistema controlado individualmente pelos aprendentes pressupõe não só sujeitos autónomos, mas também dotados de racionalidade estratégica, talvez mesmo olímpica, como criticaria Herbert Simon (1957), para desenhar rotas individuais ótimas de aprendizagem'. Neste contexto, o autor propõe e defende que nesta transição a posição "mais aceitável [é] admitir uma 
situação híbrida e complexa, tipicamente de transição"(idem, ibidem). Esta transição para a aprendizagem ao longo da vida vem dar resposta às mutações político-económico e sociais decorrentes da crise do Estado-Providência nos países centrais e pelo consequente fim do pleno emprego que veio alterar as condições inerentes aos vínculos laborais, ao mesmo tempo que se apela a uma maior coesão social de modo a evitar as fraturas sociais decorrentes das próprias alterações laborais e do aumento do desemprego.

A emergência de um "novo espírito do capitalismo” (Bolthanski \& Chiapello, 1999), renunciou a uma organização do trabalho assente em vínculos estáveis para conferir um certo protagonismo ao indivíduo, à flexibilidade, à polivalência, ao trabalho por projeto. Neste contexto, a aprendizagem ao longo da vida vem responder aos desafios lançado por este novo espírito, valorizando o indivíduo e as suas competências. Esta valorização repousa numa lógica meritocrática onde o aprender a ser é substituído pelo aprender a ter (Canário, 2001) pelas competências e pelo apoio ao processo de produção capitalista. Este novo paradigma da aprendizagem ao longo da vida manifesta-se numa era bem diferente da do movimento da educação permanente, sendo antes marcada pela ascensão das políticas neo-liberais e como uma solução que visa responder aos novos desafios da globalização hegemónica. Nesta visão, a aprendizagem assume um carácter fundamentalmente “estratégico” (Griffin, 1999), da nova economia mundial. A retórica da aprendizagem, no quadro de uma agenda globalizada, reconcetualiza conceitos e imbui novos significados às dimensões educativas, as quais devem ser lidas em função das tendências emanadas pela agenda global e que pressionam a educação num caminho orientado por valores inerentes ao mundo mercantil e empresarial onde o conceito de competência adquire um estatuto ímpar na persecução dos mandatos da aprendizagem ao longo da vida.

\section{Conclusão}

A ideia da aprendizagem ao longo da vida no seio da União Europeia tem vindo a estar vinculada a uma lógica económica. É nesta nova versão da aprendizagem que a União Europeia tem investido, desde logo em 1996 ao designar o Ano Europeu da Aprendizagem ao longo da vida e a partir do qual se intensificou o uso deste conceito em diversos documentos da União Europeia para a Educação, sendo a aprendizagem o princípio orientador do documento Educação e Formação 2010. Neste encadeamento, a aprendizagem ao longo da vida é um elemento central do Espaço Europeu de Educação e, deste modo, a Europa cria condições para a conquista de uma posição económica e cultural mundial, onde a educação cede lugar à aprendizagem.

Em síntese, os documentos indicam-nos que através da aposta na educação de adultos alicerçada no paradigma da aprendizagem ao longo da vida, a Europa cria condições para o desenvolvimento do Espaço Europeu de Educação e para a conquista de uma posição privilegiada, económica e cultural, a nível mundial. Uma das tónicas dominantes, transversal a muitos documentos, é precisamente o enfoque nas dimensões economicistas através de uma subordinação da educação de adultos a princípios de natureza económica e individuais, negligenciando as dimensões associadas a uma vertente mais humanista e emancipatória da educação.

\section{Referências}

ANTUNES, Fátima (2004). Políticas Educativas Nacionais e Globalização. Novas Instituições e Processos Educativos. Braga: Universidade do Minho. ANTUNES, Fátima (2008). A Nova Ordem Educacional - Espaço Europeu de Educação e Aprendizagem ao Longo da Vida. Coimbra: Almedina.

ÁVILA, Patrícia. A Literacia dos Adultos Competências-Chave na Sociedade do Conhecimento. Lisboa: Celta, 2008.

BARROS, Rosanna. Genealogia dos Conceitos em Educação de Adultos: Da Educação Permanente à Aprendizagem ao Longo da Vida - Um estudo sobre os fundamentos político-pedagógicos da prática educacional. Chiado Editora, 2011.

BOLTANSKI, Luc \& CHIAPELLO, Eve (1999). Le Nouvel Esprit du Capitalism. Paris: Gallimard.

CANÁRIO, Rui (2001). “Adultos - da escolarização à educação"; in Revista Portuguesa de Pedagogia, ano 35-1, pp. 85-100.

CAVACO, Cármen. Adultos pouco escolarizados Políticas e Práticas de Formação. Lisboa: Educa, 2009.. DALE, Roger (2001). "Globalização e educação: demonstrando a existência de uma 'cultura educacional mundial comum' ou localizando uma 'agenda globalmente estruturada para a educação’?”. Educação, Sociedade, \& Cultura, n. ${ }^{\circ} 16$, pp. 133-169.

DALE, Roger (2008). "Construir a Europa através de um Espaço Europeu de Educação"; in Revista Lusófona de Educação, n. ${ }^{\circ}$ 11, 2008, pp. 13-30.

ESTÊVÃO, Carlos. "Educação, globalizações e cosmopolitismos: novos direitos, novas desigualdades”; in Revista Portuguesa de Educação, 22(2), 2009, pp. 35-52.

ESTÊVÃO, Carlos. "Ideologia e Gestão das Competências” in Teoria e Prática da Educação. Maringá: Universidade Estadual de Maringá. , v. 6, nº13, 2003, pp. 209-357.

GRIFFIN, Colin (1999). "Lifelong learning and social democracy”. International Journal of Lifelong Education, v. 18, n. 5, pp. 329-342.

GUIMARÃES, Paula (2010). Políticas de educação de adultos em Portugal (1999-2006) - A emergência da educação para a competitividade. Braga: Universidade do Minho /Instituto de Educação (Tese de Doutoramento).

LIMA, Licínio (2010). “A Educação faz tudo? Critica ao pedagogismo na 'sociedade da aprendizagem””; in Revista Lusófona de Educação, n. ${ }^{\circ}$ 15, pp. 41-54.

TEODORO, António. "Organizações internacionais e políticas educativas nacionais: A emergência de novas formas de regulação transnacional, ou de uma globalização de baixa intensidade”. In: STOER, Stephen. 
R., CORTESÃO, Luiza \& CORREIA, José A. (orgs). Transnacionalização da educação: Da Crise da Educação à "educação" da crise. Porto: Afrontamento, 2001, pp. 126-158.

\section{Documentos eletrónicos:}

COMISSÃO DAS COMUNIDADES EUROPEIAS

(2000). Memorando sobre a aprendizagem ao Longo da

Vida. Documento de Trabalho dos Serviços da Comissão. Bruxelas, 30.10.2000 SEC (2000) 1832, In http://www.alv.gov.pt/info2.asp, [consultado em 2007/01/10)].
COMISSÃO DAS COMUNIDADES EUROPEIAS (2001). Tornar o espaço europeu de aprendizagem ao longo da vida uma realidade. Comunicação da Comissão de 21/11/2001 (COM(2001) 678 final). Bruxelas. In http://ec.europa.eu/education/policies/lli/life/commun ication/com_pt., [consultado em 2007/01/10].

COMISSÃO DAS COMUNIDADES EUROPEIAS (2006). Educação de Adultos: nunca é tarde para aprender. Comunicação da Comissão. Bruxelas. In. Eurlex.europa.Eu/LexUriServ/LexUriServ.do?uri=COM :2006:0614:FIN:PT,pdf [consultado em 2007/01/10] . 